\title{
Downregulation of Putative Tumor Suppressor Gene TSC-22 in Human Brain Tumors
}

\author{
KATHERINA O. SHOSTAK, MS, ${ }^{1}$ VLADIMIR V. DMITRENKO, PhD, ${ }^{1}$ OLEG M. GARIFULIN, PhD, ${ }^{1}$ \\ VLADIMIR D. ROZUMENKO, MD, DSc, ${ }^{2}$ OLEXIY V. KHOMENKO, MD, PhD, ${ }^{2}$ YURIY A. ZOZULYA, MD, DSc, ${ }^{2}$ \\ GÜNTHER ZEHETNER, PhD, ${ }^{3}$ AND VADYM M. KAVSAN, PhD, DSc ${ }^{1}$ * \\ ${ }^{1}$ Institute of Molecular Biology and Genetics, Kiev, Ukraine \\ ${ }^{2}$ Romodanov Institute of Neurosurgery, Kiev, Ukraine \\ ${ }^{3}$ Max-Planck Institute for Molecular Genetics, Berlin, Germany
}

Background and Objectives: Our objective was to identify differentially expressed genes involved in the pathogenesis of glioblastoma multiforme (GBM).

Methods: Screening of arrayed human fetal brain and human postnatal brain cDNA libraries was performed by differential hybridization with glioblastoma multiforme and human normal brain cDNAs.

Results: Repeated differential hybridization of more than 100 cDNA clones selected by primary screening and analysis of RNA from adult normal brain and glial tumors showed 16 nucleotide sequences differentially expressed between normal brain and brain tumors. Among others, decreased content in astrocytic tumors was determined for TSC-22 mRNA corresponding to cDNA in the ICRFp507J1041 clone from human fetal brain cDNA library. Northern blot hybridization of RNA from different human brain tumors showed very low amounts of TSC-22 mRNA in most investigated samples of GBM, anaplastic astrocytoma, and some other tumors. Complete lack of expression of TSC-22 occurred in one sample of anaplastic astrocytoma, as well as in meningioma, brain sarcoma, sarcomatous meningioma, and oligodendroglioma. The differential expression of TSC-22 gene was confirmed by semiquantitative RT-PCR in 15 samples of astrocytomas WHO grade II-IV and three samples of normal brain.

Conclusions: Significantly decreased levels of TSC-22 mRNA in human brain and salivary gland tumors and antiproliferative role of TSC-22 strongly suggest a tumor suppressor role for TSC-22.

J. Surg. Oncol. 2003;82:57-64. () 2002 Wiley-Liss, Inc.

KEY WoRDs: glioblastoma multiforme; astrocytoma; differential hybridization; high-density cDNA filter arrays; differential expression

\section{INTRODUCTION}

The current picture of the molecular basis of human brain tumors presents a complex interplay between multiple genetic events involving nonrandom chromosomal anomalies, activation of protooncogenes, inactivation of tumor suppressor genes, and the aberrant expression of growth factors and their receptors. Epidermal growth factor receptor (EGFR), as well as platelet-derived growth factor (PDGF) and its receptors, have been characterized as contributing oncogenes. Several investigative groups have provided cytogenetic and molecular genetic evidence for the existence of unidentified putative tumor suppressor genes on chromosomal arms 1p, 9p, 10q, 11p,
$13 \mathrm{q}, 17 \mathrm{p}, 19 \mathrm{q}$, and $22 \mathrm{q}$, in addition to known tumor suppressor genes [1-7].

However, present knowledge recognizes only a fraction of the biological mechanisms assumed to initiate and promote brain tumor formation. The candidate gene approach, correlating common genetic alterations found

\footnotetext{
Grant sponsor: NATO Collaborative Linkage; Grant number: 977284.

*Correspondence to: V.M. Kavsan, PhD, DSc, Institute of Molecular Biology and Genetics, 150 Zabolotnogo Street, Kiev 03143, Ukraine. Fax: 380-44-266-07-59. E-mail: kavsan@nbi.com.ua

Accepted 10 September 2002

DOI 10.1002/jso. 10180

Published online in Wiley InterScience (www.interscience.wiley.com).
} 
in human brain tumors with outcome or response to treatment, has yielded contradictory results. A more comprehensive approach is to include gene expression in the analysis in order not only to concentrate on structural alterations, but also to encompass regulatory differences. Identification and characterization of novel molecular markers or genes either induced or repressed in human brain tumors will contribute to understanding the mechanisms of tumor initiation and progression. Better knowledge of such mechanisms is likely to improve diagnostic and prognostic evaluation, and is necessary to define biological targets for the design of comprehensive therapeutic approaches. Predictive markers would be extremely helpful in identifying patients who would benefit from specific treatments.

In this work, the TSC-22 gene (transforming growth factor- $\beta$ [TGF- $\beta 1$ ]-stimulated clone 22 ), originally identified as a primary response gene [8], was found to have a significantly decreased level of the expression in some human brain tumors, as compared with that in normal brain. The present work describes the results in accordance with previously published data, indicating a potential tumor suppressor role of the TSC-22 gene.

\section{MATERIALS AND METHODS}

\section{Human Tissues and cDNA Libraries}

Brain tumor and normal tissues were procured from tumor tissue bank maintained by the Romodanov Institute of Neurosurgery, Kiev, Ukraine. Of 27 tumors used in this work, 23 were primary tumors, and 4 were recurrent tumors. One patient with a primary tumor received chemotherapy before surgical excision. Surgical specimens of human fetal brain were supplied by Center of Embryonic Tissues, Kiev. High-density cDNA filter arrays of human fetal and infant brain cDNA libraries came from The Resource Center/Primary Database (RZPD) of the German Human Genome Project (Max Planck Institute for Molecular Genetics, Berlin and Deutsches Krebsforschungszentrum, Heidelberg).

\section{Differential Hybridization of cDNA Libraries}

Differential hybridization of ${ }^{32} \mathrm{P}$-labeled human glioblastoma and normal brain cDNAs to gridded human brain cDNA libraries was performed as described in our previous articles [9-11]. Total cDNA probes for differential hybridization were synthesized on the total RNAs, isolated from surgical specimens of human normal brain and primary astrocytic tumors: glioblastoma multiforme (GBM) and anaplastic astrocytoma. The conditions of oligo(dT)-primed cDNA synthesis were as described in standard procedure [12], but the concentration of dCTP was reduced to $25 \mu \mathrm{M}$, and $150-200 \mu \mathrm{Ci}$ of $\left[\alpha-{ }^{32} \mathrm{P}\right] \mathrm{dCTP}$ was added to the reaction to obtain cDNA probes with high specific activity. cDNA filter arrays were consequentially hybridized with tumor and normal brain cDNA probes and the coordinates of cDNA clones with altered hybridization signals between tumor and control cDNAs were determined on the gridded arrays. The clones were requested from RZPD (http:// www.rzpd.de); repeated differential hybridization of these clones was carried out.

\section{RNA Isolation}

Total RNA was isolated from liquid nitrogen-frozen surgical specimens of human brain tumors and normal tissues, as well as from samples of normal fetal human brain by acid guanidinium thyiocyanate-phenol-chlorophorm extraction [13]. (Surgical specimens of histologically normal brain tissue adjacent to tumor were used as a source for normal adult human brain RNA.)

\section{Northern Blot Analysis}

Total RNA (20 $\mu \mathrm{g}$ per lane) was separated electrophoretically in $1.5 \%$ agarose gel containing $2.2 \mathrm{M}$ formaldehyde and was then transferred to a Hybond-N nylon membrane (Amersham Pharmacia Biotech). The membrane was hybridized with a ${ }^{32} \mathrm{P}$-labeled human TSC-22 cDNA probe $\left(10^{6} \mathrm{cpm} / \mathrm{ml}\right)$ in $50 \%$ formamide; $5 \times$ SSC; $5 \times$ Denhardt's solution; $0.1 \%$ sodium dodecyl sulfate (SDS), and $100 \mu \mathrm{g} / \mathrm{ml}$ salmon sperm DNA at $42^{\circ} \mathrm{C}$ overnight. Extensive washing was performed: twice with $2 \times \mathrm{SSC}, 0.1 \% \mathrm{SDS}$ for $15 \mathrm{~min}$ at room temperature; once with $2 \times$ saline sodium citrate (SSC), $0.1 \%$ SDS for $30 \mathrm{~min}$ at $65^{\circ} \mathrm{C}$; and finally with $0.2 \times \mathrm{SSC}, 0.1 \%$ SDS for $30 \mathrm{~min}$ at $65^{\circ} \mathrm{C}$. Subsequently, the membrane was exposed to radiographic film with an intensifying screen at $-70^{\circ} \mathrm{C}$. The membrane was rehybridized sequentially with a ${ }^{32} \mathrm{P}$-labeled human $\beta$-actin cDNA probe as a control of gel loading. Densitometric analysis of signals was performed by Scion Image 1.62c program.

\section{Southern Blot Analysis}

Genomic DNA from human astrocytic tumors and from blood samples of tumor patients and unrelated individuals was isolated by phenol/chloroform extraction [12], digested with HindIII endonuclease, separated by electrophoresis in $0.6 \%$ agarose gel in $1 \times \mathrm{TBE}$ buffer, and transferred onto a Hybond-N nylon membrane (Amersham Pharmacia Biotech). The membrane was hybridized with a ${ }^{32} \mathrm{P}$-labeled human TSC-22 cDNA $\left(10^{6} \mathrm{cpm} / \mathrm{ml}\right)$ in $50 \%$ formamide; $5 \times \mathrm{SSC} ; 5 \times$ Denhardt's solution; $0.1 \%$ SDS and $100 \mu \mathrm{g} / \mathrm{ml}$ salmon sperm DNA at $42^{\circ} \mathrm{C}$ overnight. Washing conditions: 
twice with $2 \times \mathrm{SSC}, 0.1 \% \mathrm{SDS}$ for $30 \mathrm{~min}$ at room temperature; once with $2 \times \mathrm{SSC}, 0.1 \% \mathrm{SDS}$ for $30 \mathrm{~min}$ at $65^{\circ} \mathrm{C}$; and finally with $0.2 \times \mathrm{SSC}, 0.1 \% \mathrm{SDS}$ for $30 \mathrm{~min}$ at $65^{\circ} \mathrm{C}$. The filter was exposed to radiographic film with an intensifying screen at $-70^{\circ} \mathrm{C}$.

\section{Semiquantitative RT-PCR}

Semiquantitative reverse transcription-polymerase chain reaction (RT-PCR) with TSC-22-specific primers was performed on normal brain and brain tumor RNA samples as described by Rae et al. [14]. Equal amounts of total cellular RNA (10 $\mu \mathrm{g}$ each) were reverse transcribed into cDNA with an oligo(dT) primer. In a $20-\mu 1$ reaction, PCR was performed with cDNA synthesized from $0.5 \mu \mathrm{g}$ of total RNA, $2 \mathrm{U}$ Taq-polymerase, $1 \times$ PCR buffer, $0.2 \mathrm{mM}$ dNTPs, and $1 \mu \mathrm{M}$ TSC-22-specific primers. Thermal cycling parameters were $94^{\circ} \mathrm{C}$ for $30 \mathrm{~s}$, $56^{\circ} \mathrm{C}$ for $1 \mathrm{~min}$, and $72^{\circ} \mathrm{C}$ for $1 \mathrm{~min}$ for 30 cycles, followed by a further $7 \mathrm{~min}$ at $72^{\circ} \mathrm{C}$. The number of cycles was then decreased until the PCR product amplification rate was in the linear phase ( 27 cycles). Amplified products were electrophoresed in a $2 \%$ agarose gel and transferred to a nylon membrane. The membrane was subsequently hybridized with a ${ }^{32} \mathrm{P}$-labeled TSC-22 cDNA probe $\left(10^{6} \mathrm{cpm} / \mathrm{ml}\right)$ in $50 \%$ formamide to detect very low quantities of TSC-22 mRNA in some tumor samples.

\section{Nucleotide Sequence Analysis}

Nucleotide sequences of cDNA inserts were determined according to the Sanger method [15]. The GenBank and EMBL databases were searched for overall nucleic acid homologies by the BLAST program via the Internet.

\section{RESULTS}

\section{Identification of the Genes Differentially Expressed Between Normal Brain and Brain Tumors}

As with subtractive hybridization techniques [16], differential hybridization is advantageous in that it does not require a priori sequence information, but it is unique in that both commonly and specifically expressed mRNAs in multiple tissues or cell samples can be compared simultaneously. Thus, in the same experiment, genes expressed only in normal tissues (e.g., tumor suppressor genes), as well as genes that are tumor specific (e.g., tumor markers, activated oncogenes), can be identified [17].

Differential hybridization of arrayed human fetal brain and human postnatal brain cDNA libraries with total cDNA probes of GBM and normal adult brain showed more than 100 cDNA clones with differences in the intensity of hybridization. Repeated differential hybridization of cDNA clones, selected by primary screening, and nucleotide sequence analysis of cDNA inserts allowed us to identify 16 nucleotide sequences whose expression has been changed by $3-10$-fold (for several cases, by more than 10-fold) in tumor cells. The information about these sequences is shown in Table I. The potential tumor-specific expression of isolated nucleotide sequences was verified by Northern blotting, using membranes with total RNA from brain tumors and control tissues. The total length and splice patterns of transcripts in normal human tissues and in astrocytomas of different malignancy grades were evaluated. Because of the problem presented by heterogeneous expression among individual tumors and among normal brain samples, different normal brain samples and astrocytoma tissues were subjected to comparative analysis.

TSC-22 mRNA was identified among the sequences with decreased content in the GBM. The nucleotide sequence of TSC-22 cDNA from human fetal brain cDNA clone ICRFp507J1041 is shown in Figure 1 (found under Accession No. AJ222700 in the databases). The nucleotide sequence of ICRFp507J1041 cDNA is identical to previously published TSC-22 cDNA nucleotide sequence $[18,19]$ but due to the alternative processing of the 3'-untranslated region the ICRFp507J1041 cDNA is two nucleotides shorter than the published TSC-22 cDNA. The heterogeneity of polyadenylation sites generated under the influence of a single polyadenylation signal was described by us previously for transcripts from three different genes in human fetal liver [20].

\section{Decreased Expression of TSC-22 Gene in Brain Tumors}

Northern blot hybridization was carried out in order to examine the level and size of the TSC-22 gene transcript in individual human brain tumors (Fig. 2). Four different samples of histologically normal adult brain, adjacent to the tumor and ablated due to necessity in the course of surgery, were used as a source of RNA for comparison of gene expression in normal brain. The radiolabeled TSC22 cDNA hybridized to a major band of RNA of $\sim 1.8-\mathrm{kb}$ size in normal tissues, e.g., heart and kidney (lanes 1 and 2 ) and adult normal brain (lanes 3-6). However, amounts of the $1.8-\mathrm{kb}$ mRNA were varied in the tumor tissues tested. Comparison of the hybridization signals with the TSC-22 cDNA probe clearly showed a significant decrease in TSC-22 mRNA contents in three of four GBM samples (lanes 8-10). There was also a decreased level of the TSC-22 mRNA in the fourth GBM (lane 7). A very low level of TSC-22 mRNA was detected in three of five anaplastic astrocytomas (lanes 11, 14, 18). Gene expression level was also decreased in three World Health Organization (WHO) grade II astrocytomas (lanes 13, 
TABLE I. Nucleotide Sequences Differentially Expressed Between Human Adult Normal Brain and Astrocytic Gliomas

\begin{tabular}{llc}
\hline Clones & \multicolumn{1}{c}{ Identity/highest homology } & Expression in glioblastoma \\
\hline ICRFp507M243 & mt 16S iRNA & Increased \\
ICRFp507H2345 & mt 16S rRNA & Increased \\
COLUp553J0232 & mt 16S rRNA & Increased \\
COLUp553J2484 & mt 16S rRNA & Increased \\
COLUp553I0714 & mt 12S rRNA & Increased \\
COLUp553P2336 & mt 12S rRNA & Increased \\
ICRFp507G1815, & 28S rRNA & Increased \\
COLUp553C1116 & 28S rRNA & Increased \\
ICRFp507I0511 & Apolipoprotein E & Increased \\
ICRFp507B2047 & DNA binding protein B & Increased \\
ICRFp507F0246 & TRAF6-like protein (contains Alu repeat) & Increased \\
ICRFp507G2490 & Human homologue to hypothetical C. Caenorhabditis & Increased \\
& elegans 9.8-kDa protein & \\
ICRFp507C1134 & Novel (contains Alu repeat) & Increased \\
ICRFp507F0552 & Novel (contains Alu repeat) & Increased \\
ICRFp507M1080 & Novel (contains Alu repeat) & Increased \\
ICRFp507J2448 & MLL septin-like fusion protein & Increased \\
ICRFp507G124 & FX protein & Decreased \\
ICRFp507J1041 & TSC-22 & Decreased \\
ICRFp507L1033 & Cullin 1 & Decreased \\
ICRFp507C063 & Novel, chromosome 13 & Decreased \\
ICRFp507O073 & Novel, chromosome 2 & Decreased \\
\hline
\end{tabular}

20, 21), although to a lesser extent than in GBMs and anaplastic astrocytomas. A very low level of TSC-22 mRNA was also observed in one benign meningioma (lane 17). It was not detectable at all in some other types of malignant tumors, i.e., meningioma sarcomatous, brain sarcoma, and WHO grade II-III oligodendroglioma (lanes 22, 23, and 24, correspondingly).

Subsequent semiquantitative RT-PCR analysis was performed for verification of differential expression of TSC-22 gene between normal brain and astrocytic tumors. RT-PCR analysis confirmed the results obtained by Northern hybridization and demonstrated decreased expression in astrocytomas grade II and III and absence of the expression of TSC-22 in all 8 samples of GBM analyzed (Fig. 3).

\section{TSC-22 Gene Locus Does Not Have Deletions in Astrocytic Tumors}

Southern blot hybridization of genomic DNA from astrocytomas of different malignancy grades and from blood samples of tumor patients and unrelated individuals was performed to examine possible deletions at the TSC22 gene locus. HindIII-digested DNA was hybridized to a ${ }^{32}$ P-labeled fragment of ICRFp507J1041 cDNA, synthesized by PCR, using primers pr1 and pr2 (positions of the primers are indicated in Fig. 1). This analysis did not show differences in the hybridization pictures of tumor DNA (Fig. 4), or of blood DNA from tumor patients and nontumor DNA of unrelated individuals. Two hybridized 4.7- and 2.2-kb fragments were shown in all DNA samples. The presence of a $4.7-\mathrm{kb}$ fragment is in accordance with the genomic sequence of the TSC-22 gene (Accession No. AL138960). An additional 2.2-kb fragment may represent the gene from another allele.

\section{DISCUSSION}

In the present study, we have identified the TSC-22 gene-one of the genes characterized by differential hybridization as differentially expressed between normal human brain and human brain tumors. We found that expression of this gene was significantly decreased in astrocytomas of different malignancy grades and in some other types of brain tumors.

The TSC-22 gene belongs to the family of early response genes and was originally isolated from mouse osteoblastoma cDNA library as a gene that was stimulated by transforming growth factor- $\beta 1$ (TGF $\beta 1$ stimulated clone 22) [8]. Its expression grows rapidly in response to cell treatment by bacterial lipopolysaccharides (LPS), some cytokines (TGF- $\beta 1$, tumor necrosis factor- $\alpha$ [TNF- $\alpha$ ], and interferon- $\gamma$ [IFN- $\gamma]$ ] [19], and other inductors (dexamethasone, cholera toxin, and phorbol 12-myristate 13-acetate [PMA]) [8]. TSC-22 was shown to be one of the target genes for progesterone [21]. Induction by progesterone suggests the presence of the progesterone response element in the TSC-22 gene 
CGCCTCTTCACGGCACTGGGATCCGCATCTGCCTGGGATCATCAAGCCCTAGAAGCTGGG TTTCTTTAAATTAGGGCTGCCGTTTTCTGTTTCTCCCTGGGCTGCGGAAAGCCAGAAGAT TTTATCTAGCTTATACAAGGCTGCTGGTGTTCCCTCTTTTTTCCACGAGGGTGTTTTTG $\begin{array}{llllllllllllllllll}M & K & S & Q & W & C & R & P & V & A & M & D & L & G & V & Y & Q\end{array}$ GCTGCAATTGCATGAAATCCCAATGGTGTAGACCAGTGGCGATGGATCTAGGAGTTTACC pr3

$\begin{array}{llllllllllllllllllll}L & R & H & F & S & I & S & F & L & S & S & L & L & G & T & E & N & A & S & V\end{array}$ AACTGAGACATTTTTCAATTTCTTTCTTGTCATCCTTGCTGGGGACTGAAAACGCTTCTG $\begin{array}{llllllllllllllllllll}R & L & D & N & S & S & S & G & A & S & V & V & A & I & D & N & K & I & E & Q\end{array}$ TGAGACTTGATAATAGCTCCTCTGGTGCAAGTGTGGTAGCTATTGACAACAAAATCGAGC $\begin{array}{llllllllllllllllllll}A & M & D & L & V & K & S & H & L & M & Y & A & V & R & E & E & V & E & V & I\end{array}$ AAGCTATGGATCTAGTGAAAAGCCATTTGATGTATGCGGTCAGAGAAGAAGTGGAGGTCC

$\begin{array}{llllllllllllllllllll}K & E & Q & I & K & E & L & I & E & K & N & S & Q & I & E & Q & E & N & N & L\end{array}$ TCAAAGAGCAAATCAAAGAACTAATAGAGAAAAATTCCCAGCTGGAGCAGGAGAACAATC

$\begin{array}{llllllllllllllllllll}L & K & T & L & A & S & P & E & Q & L & A & Q & F & Q & A & Q & L & Q & T & G\end{array}$ TGCTGAAGACACTGGCCAGTCCTGAGCAGCTTGCCCAGTTTCAGGCCCAGCTGCAGACTG $\begin{array}{llllllllllllllllllllllllllllllll}S & P & P & A & T & T & Q & P & Q & G & T & T & Q & P & P & A & Q & P & A & S\end{array}$ GCTCCCCCCCTGCCACCACCCAGCCACAGGGCACCACACAGCCCCCCGCCCAGCCAGCAT Q $G \quad S \quad G \quad P \quad T$ A * CGCAGGGCTCAGGACCAACCGCATAGCTGCCTATGCCCCCGCAGAACTGGCTGCTGCGTG TGAACTGAACAGACGGAGAAGATGTGCTAGGGAGAATCTGCCTCCACAGTCACCCATTTC ATTGCTCGCTGCGAAAGAGACGTGAGACTGACATATGCCATTATCTCTTTTCCAGTATTA AACACTCATATGCTTATGGCTTGGAGAAATTTCTTAGTTGGGTGAATTAAAGGTTAATCC GAGAATTAGCATGGATATACCGGGACCTCATGCAGCTTGGCAGATATCTGAGAAATGGTT TAATTCATGCTCAGGAGCTGTGTGCCTTTCCATCCCTTCCGGCTCCCTACCCCTCACTTC pr1

CAAGGGTTCTCTCTCCTGCTTGCGCTTAGTGTCCTACATGGGGTTGTGAAGCGATGGAGC TCCTCACTGGACTCGCCTCTCTCCTCTCCTCCCCCCAGGAGGAACTTGAAAGGAGGGTAA AAAGACTAAAATGAGGGGGAACAGAGTTCACTGTACAAATTTGACAACTGTCACCAAAAT TCATAAAAAACAATAGTACTGTGCCTCTTTCTTCTCAAACAATGGATGACACAAAACTAT GAGAGTGACAAAATGGTGACAGGTAGCTGGGACCTAGGCTATCTTACCATGAAGGTTGTT TTGCTTATTGTATATTTGTGTATGTAGTGTAACTATTTTGTACAATAGAGGACTGTAACT ACTATTTAGGTTGTACAGATTGAAATTTAGTTGTTTCATTGGCTGTCTGAGGAGGTGTGG ACTTTTATATATAGATCTACATAAAAACTGCTACATGACAAAAACCACACCTAAACCCCT TTTAAGAATTTGGCACAGTTACTCACTTTGTGTAATCTGAAATCTAGCTGCTGAATACGC TGAAGTAAATCCTTGTTCACTGAAGTCTTTCAATTGAGCTGGTTGAATACTTTGAAAAAT GCTCAGTTCTAACTAATGAAATGGATTTCCCAGTAGGGGTTTCTGCATATCACCTGTATA pr2

GTAGTTATATGCATATGTTTCTGTGCATGTTCTCTACACAATTGTAAGGTGTCACTGTAT TTAACTGTTGCACTTGTCAACTTTCAATAAAGCATATAAATGTTG (A) n

Fig. 1. Nucleotide sequence of TSC-22 cDNA from clone ICRFp507J1041 and predicted amino acid sequence of TSC-22 protein. The amino acid sequence is presented in the single-letter code, above the first positions of the codons. Four leucine and one valine residue, which form putative leucine zipper structure, and polyadenylation signal are underlined. Positions of polymerase chain reaction (PCR) primers (pr1, pr2, pr3, and $\mathrm{pr} 4$ ) are indicated with arrows.

promoter. The growth of the expression of the TSC-22 gene in the response to dexamethasone, a synthetic activator of the glucocorticoid receptor [8], supports this suggestion.

TSC-22 contains a leucine zipper motif. It has been hypothesized as a transcription factor [8], although it does not contain a classic DNA-binding domain such as those in the bZip or bHLH-Zip families. TSC-22 was determined to be the transcription regulator of the $\mathrm{C}$-type natriuretic peptide gene, interacting with GC-rich elements of its promoter [19]. Recent studies showed transcription repressor activity of TSC-22, which can form 


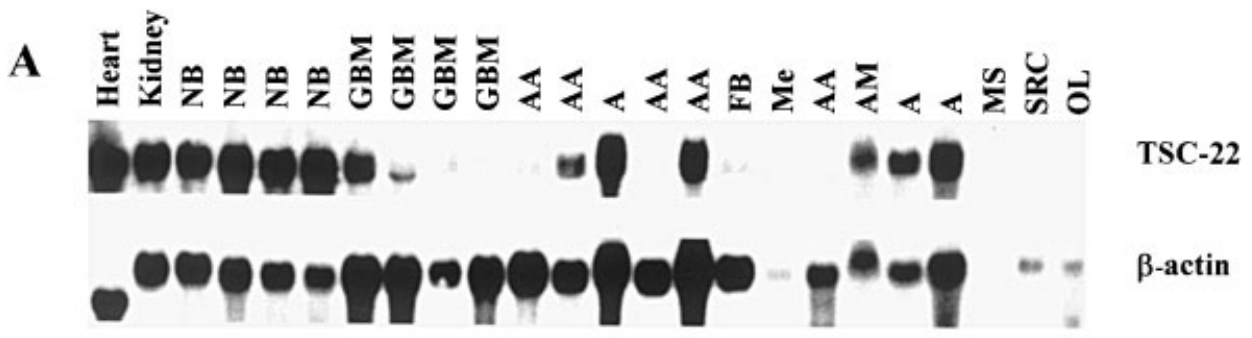

B

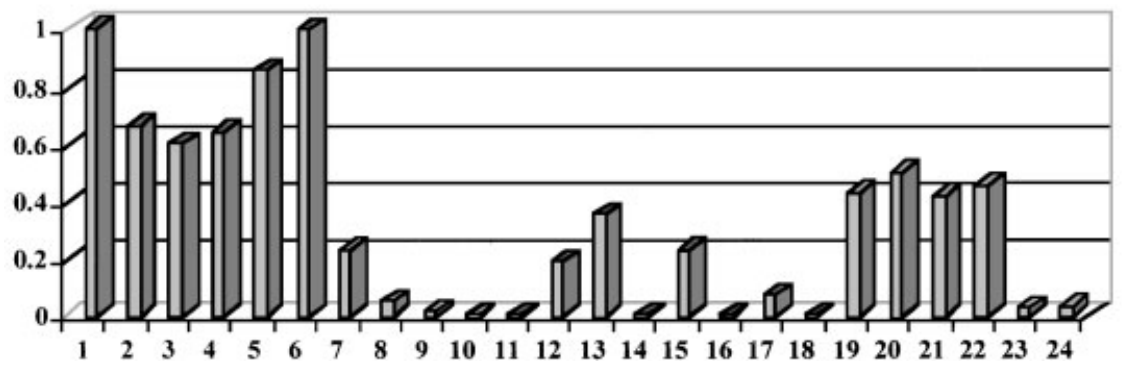

Fig. 2. Expression of TSC-22 mRNA in normal human tissues and in brain tumors. A: Northern blot hybridization of ${ }^{32} \mathrm{P}-\mathrm{labeled}$ ICRFp507J1041 cDNA probe with total RNA from: lane 1, adult heart; lane 2, adult kidney; lanes 3-6, samples of adult normal brain; lanes 7-10, samples of GBM; lanes 11,12,14,15,18, samples of anaplastic astrocytoma; lane 16, fetal brain (6 weeks old); lanes 13, 20, 21, samples of astrocytoma (WHO grade II); lane 17, benign meningioma; lane 19, anaplastic meningioma; lane 22, meningioma sarcomatous; lane 23, brain sarcoma; lane 24, oligodendroglioma (WHO grade II-III). B: Bar graph showing relative expression of TSC-22 gene after correction for gel loading based on $\beta$-actin gene expression.

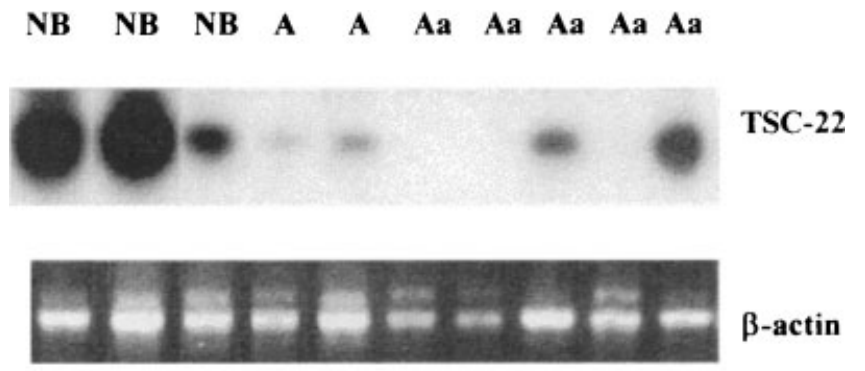

GB GB GB GB GB GB GB GB

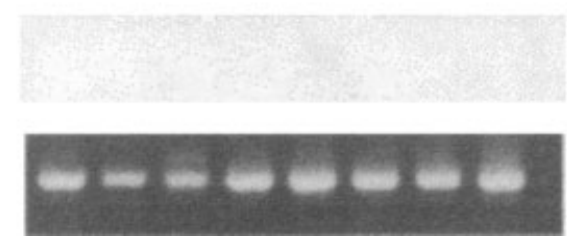

TSC-22

$\beta$-actin

Fig. 3. Semiquantitative RT-PCR for TSC-22 mRNA. PCR was carried out with primers pr3 and pr4 indicated in Fig. 1. PCR with primers to $\beta$-actin gene was used as a control for cDNA synthesis. TSC-22 PCR products were hybridized subsequently with ${ }^{32} \mathrm{P}$-labeled ICRFp507J1041 cDNA probe. Lanes 1-3, samples of adult normal brain; lanes 4,5, samples of astrocytoma (WHO grade II); lanes 6-10, samples of anaplastic astrocytoma; lanes 11-18, samples of GBM. homodimers via its leucine zipper domain [22]. It is possible that TSC-22 may form heterodimers with basic leucine zipper transcription factors and that it may repress classical transcription activators as a dominant negative regulator, such as helix-loop-helix proteins Id1-Id4 [23].

Decreased content, and even complete absence, of TSC-22 mRNA were also found in benign and malignant human salivary gland tumors, as compared with that in the normal salivary gland [24]. In contrast, TSC-22 displayed a negative regulatory effect on cell proliferation.

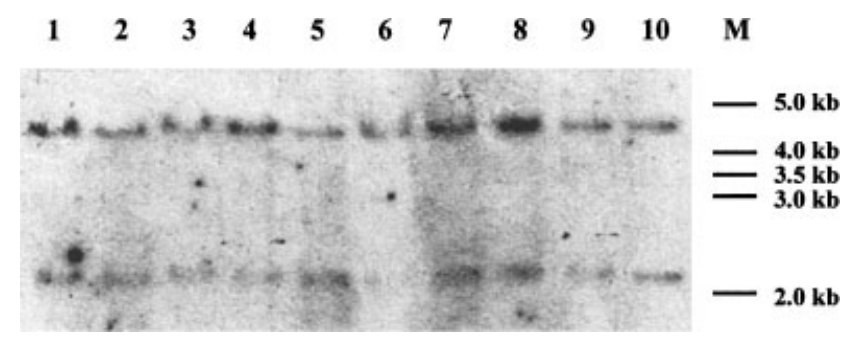

Fig. 4. Southern analysis of TSC-22 gene in DNA from tumor samples. Southern blot was hybridized with ${ }^{32} \mathrm{P}$-labeled fragment of ICRFp507J1041 cDNA, synthesized by PCR with primers pr1 and pr2 indicated in Fig. 1. Each lane contains $10 \mu \mathrm{g}$ of HindIII-digested DNA from: lanes 1-3,5,8, GBMs; lanes 4,6,7, anaplastic astrocytomas; lane 9, normal brain; lane 10, oligodendroastrocytoma. Positions of fragments of DNA size marker (MassRuler DNA Ladder, Mix, Fermentas) are shown on the right side. 
The investigation of apoptotic cell death mechanism in the human gastric carcinoma cell line HSC-39 after treatment with TGF- $\beta 1$ showed that TSC- 22 can play the role of the mediator of TGF- $\beta 1$ signaling pathway to apoptosis [25]. HSC-39 cells transfected with a TSC22-expressing vector showed a significant decrease in cell viability and elicited apoptotic cell death through the activation of CPP32-like protease because the synthetic peptide inhibitor, specific to CPP32-type protease, protected the cells against death. Treatment of human salivary gland cancer cell line TYS under quiescent conditions by antisense oligonucleotide against TSC-22 mRNA stimulated the growth of TYS cells; however, under growing conditions, the antisense oligonucleotide did not affect cell growth [26]. Furthermore, the antiproliferative effect of anticancer drug vesnarinone was suppressed by the antisense oligonucleotide. These results also indicate that TSC-22 may be a negative regulator of cell growth and that it may play an important role in the antiproliferative effect of vesnarinone. Upregulation of the TSC-22 protein affected neither in vitro nor in vivo growth of TYS cells, but downregulation of TSC-22 markedly enhanced their growth in vitro and in vivo [24].

The TSC-22 gene was mapped to chromosome 13 at position q14 [18]. The location of this gene on the chromosome 13 may be determined more precisely by the NCBI Map Viewer. The TSC-22 gene has been localized in the 13q13.2-13q13.3 region. The loss of the chromosome arm $13 q$ occurs in up to $50 \%$ of human astrocytomas, suggesting the presence of astrocytoma tumor suppressor gene(s) at that location [27-30]. Loss of heterozygosity $(\mathrm{LOH})$ at the retinoblastoma $(\mathrm{Rb})$ susceptibility gene locus, located on 13q14, was detected in $30 \%$ of high-grade astrocytomas, but was not detected in low-grade gliomas [27]. These results indicate that the $\mathrm{Rb}$ gene locus is targeted by the deletions in $13 q$, but they also suggest the possibility of the presence of other astrocytoma suppressor gene(s) in this region and TSC-22 gene may be one of them. We performed Southern blot hybridization of genomic DNA from astrocytomas of different malignancy grades and from blood samples of tumor patients and unrelated healthy individuals, to examine possible deletions at the TSC-22 gene locus in astrocytic gliomas. However, Southern blot analysis did not demonstrate the differences in hybridization patterns of tumor and nontumor DNA. It may be concluded that the repression of TSC-22 gene activity in tumor cells may be caused by changes in its regulation.

Thus, the significantly decreased content of TSC-22 mRNA in human brain and salivary gland tumors and the negative role of TSC-22 protein in cell proliferation suggest the possible tumor suppressor role of this gene.
Recent studies showed that the constructions expressing TSC-22 may be useful in the chemotherapy of tumors. Overexpression of TSC-22 markedly enhanced chemosensitivity of human salivary gland cancer cells in vitro and in vivo via 5-fluorouracil-induced apoptosis [31,32].

\section{ACKNOWLEDGMENTS}

The authors are grateful to Dr. N. Gridina for helpful discussion.

\section{REFERENCES}

1. Maier D, Zhang Z, Taylor E, et al.: Somatic deletion mapping on chromosome 10 and sequence analysis of PTEN/MMAC1 point to the 10q25-26 region as the primary target in low-grade and highgrade gliomas. Oncogene 1998;16:3331-3335.

2. Rosenberg EJ, Lisle DK, Burwick JA, et al.: Refined deletion mapping of the chromosome $19 \mathrm{q}$ glioma tumor suppressor gene to the D19S412-STD interval. Oncogene 1996;13:2483-2485.

3. Ino Y, Silver JS, Blazejewski L, et al.: Common regions of deletions on chromosome 22q12, 22q13.1 and 22q13.2 in human astrocytomas appear related to malignancy grade. J Neuropathol Exp Neurol 1999;58:881-885.

4. Simons A, Jeuken JW, Eleweld MJ, et al.: Isolation and characterization of glioblastoma-associated homozygously deleted DNA fragments from chromosomal region 9p21 suggests involvement of multiple tumor suppressor genes. J Pathol 1999; 189:402-409.

5. Smith JS, Tachibana I, Allen C, et al.: Cloning of a human ortholog (RPH3AL) of (RNO)Rph3al from a candidate $17 \mathrm{p} 13.3$ medulloblastoma tumor suppressor locus. Genomics 1999;59:97101.

6. Farrell WE, Clayton RN: Tumor suppressor genes in pituitary tumor formation. Baillieres Best Pract Res Clin Endocrinol Metab 1999;13:81-93.

7. Bello MJ, de Campos JM, Vaquero J, et al.: High-resolution analysis of chromosome arm $1 \mathrm{p}$ alterations in meningioma. Cancer Genet Cytogenet 2000;20:30-36.

8. Shibanuma M, Kuroki T, Nose K: Isolation of a gene encoding a putative leucine zipper structure that is induced by transforming growth factor beta1 and other growth factors. J Biol Chem 1992; 267:10219-10224.

9. Dmitrenko VV, Garifulin OM, Smikodub OI, et al.: Analysis of human genome expression by using of cDNA libraries of different tissues. Cytol Genet (Ukr) 1995;29:64-71.

10. Dmitrenko VV, Garifulin OM, Shostak KO, et al.: Characterization of different types of mRNAs expressing in human brain. Cytol Genet (Ukr) 1996;30:41-47.

11. Dmitrenko VV, Shostak KO, Garifulin OM, et al.: Changes of gene expression in human brain astrocytomas. Exp Oncol (Ukr) 1998;20:191-197.

12. Sambrook J, Fritch EF, Maniatis T: "Molecular Cloning: A Laboratory Manual." 2nd ed. Cold Spring Harbor, NY: Cold Spring Harbor Laboratory Press; 1989.

13. Chomczynski P, Sacchi N: Single step method of RNA isolation by acid guanidinium thiocyanate-phenol-chloroform extraction. Anal Biochem 1987;162:156-159.

14. Rae FK, Stephenson SA, Nicol DL, Clements JA: Novel association of a diverse range of genes with renal cell carcinoma as identified by differential display. Int J Cancer 2000;88:726732.

15. Sanger FS, Nicklen S, Coulson AR: DNA sequencing with chainterminating inhibitors. Proc Natl Acad Sci USA 1977;74:64636467.

16. Diatchenko L, Lukyanov S, Lau YF, et al.: Suppression subtractive hybridization: A versatile method for identifying 
differentially expressed genes. Methods Enzymol 1999;303:349_ 380 .

17. Nguyen C, Rocha D, Granjeaud S, et al.: Differential gene expression in the murine thymus assayed by quantitative hybridization of arrayed cDNA clones. Genomics 1995;29:207-216.

18. Jay P, Ji JW, Marsollier C, et al.: Cloning of the human homologue of the TGFbeta-stimulated clone 22 gene. Biochem Biophys Res Commun 1996;222:821-826.

19. Ohta S, Shimekake Y, Nagata K: Molecular cloning and characterization of a transcription factor for the C-type natriuretic peptide gene promoter. Eur J Biochem 1996;242:460-466.

20. Dmitrenko VV, Kavsan VM: Variability of polyadenylation sites in mRNAs from human fetal liver. FEBS Lett 1991;280:284286.

21. Kestler HA, van der Leebe B-JM, van der Saag PT, van der Burg B: Novel progesterone target genes identified by an improved differential display technique suggest that progestin-induced growth inhibition of breast cancer cells coincides with enhancement of differentiation. J Biol Chem 1997;272:16637-16643.

22. Kestler HA, Blanchetot $\mathrm{C}$, den Hertog J, et al.: Transforming growth factor beta stimulated clone TSC-22 is a member of a family of leucine zipper proteins that can homo- and heterodimerize and has transcriptional repressor activity. J Biol Chem 1999;274:27439-27447.

23. Riechmann V, van Cruchten I, Sablitzky F: The expression pattern of Id4, a novel dominant negative helix-loop-helix protein, is distinct from Id1, Id2 and Id3. Nucleic Acids Res 1994;22:749755 .

24. Nakashiro K, Kawamata H, Hino S, et al.: Down-regulation of TSC-22 (transforming growth factor beta-stimulated clone 22) markedly enhances the growth of a human salivary gland cancer cell line in vitro and in vivo. Cancer Res 1998;58:549-555.

25. Ohta S, Yanagihara K, Nagata K: Mechanism of apoptotic cell death of human gastric carcinoma cells mediated by transforming growth factor beta. Biochem J 1997;324:777-782.

26. Kawamata H, Nakashiro K, Uchida D, et al.: Induction of TSC-22 by treatment with a new anti-cancer drug, vesnarinone, in a human salivary gland cancer cell. Br J Cancer 1998;77:71-78.

27. Henson JW, Schnitker BL, Correa KM, et al.: The retinoblastoma gene is involved in malignant progression of astrocytomas. Ann Neurol 1994;36:714-721.

28. Venkatraj VS, Begemann M, Sobrino A, et al.: Genomic changes in glioblastoma cell lines detected by comparative genomic hybridization. J Neurooncol 1998;36:141-148.

29. Harada K, Nishizaki T, Ozaki S, et al.: Intratumoral cytogenetic heterogeneity detected by comparative genomic hybridization and laser scanning cytometry in human gliomas. Cancer Res 1998;58: 4694-4700.

30. Huhn SL, Mohapatra G, Bollen A, et al.: Chromosomal abnormalities in glioblastoma multiforme by comparative genomic hybridization: Correlation with radiation treatment outcome. Clin Cancer Res 1999;5:1435-1443.

31. Uchida D, Kawamata H, Omotehara F, et al.: Over-expression of TSC-22 (TGF-beta stimulated clone-22) markedly enhances 5 -fluorouracil-induced apoptosis in a human salivary gland cancer cell line. Lab Invest 2000;80:955-963.

32. Omotehara F, Uchida D, Hino S, et al.: In vivo enhancement of chemosensitivity of human salivary gland cancer cells by overexpression of TGF-beta stimulated clone-22. Oncol Rep 2000; 7:737-740. 